\title{
METHODOLOGY FOR THE DETERMINATION OF THE OPTIMAL MONITORING FREQUENCY OF ELECTRIC EQUIPMENT IN THE HYDROCARBONS SECTOR
}

\author{
OSCAR FLÓREZ-CEDIEL, JULIÁN R. CAMARGO L \& ELVIS E. GAONA G
}

Engineering Faculty, Universidad Distrital Francisco José de Caldas, Bogotá, Colombia

\begin{abstract}
This paper analyses different methodologies used to determine the optimal frequency of inspection of equipment and apply them through a case study, to analyze the value, it generates in the maintenance strategy of the equipment understudy of a production unit in the hydrocarbon sector. A brief theoretical review of the models for the calculation of the monitoring frequency and number of inspections required per year is carried out. Next, the methodologies are applied to the equipment under study, analyzing the results obtained and presenting the conclusions and recommendations of the work carried out.
\end{abstract}

KEYWORDS: Electric Equipment, Hydrocarbon, Inspection, Monitoring, Optimal Frequency

Received: Oct 04, 2020; Accepted: Oct 24, 2020; Published: Nov 23, 2020; Paper Id.: IJMPERDOCT202062

\section{INTRODUCTION}

Maintenance in the hydrocarbon sector has become increasingly important since adequate planning allows companies to generate greater value for their assets. Thus, today we talk about different types of maintenance: corrective and preventive, within which we have the predetermined maintenance or condition-based maintenance (CBM) [1]-[4], which has taken great interest in the industry because it not only seeks to prevent the occurrence of unexpected failures in the equipment but also allows monitoring the equipment with techniques that do not affect the operation and in times where the cost-benefit ratio is higher.

Therefore, for the implementation of condition-based maintenance, we propose the realization of a matrix (CBM Matrix) in which the characterization of the equipment subject to the maintenance plan of the company is made, taking into account factors such as the criticality of these within the process, technical location, cause and effect analysis, failure mode controls for each technique applied, monitoring and analysis times according to the technique, the frequency between the monitoring, among others [5]. It is a key aspect of the calculation of that frequency of monitoring since it will allow making a good balance of the necessary man-hours $(\mathrm{HH})$ to carry out the monitoring of the equipment, where it is avoided to make unnecessary maintenances and it reflects the relation benefit-cost of applying CBM in the equipment and it is generated value on the assets.

Since infrared thermography is a CBM technique that allows studying the state in which an element is without interrupting its operation in the system and is not a destructive test, it allows monitoring important elements for the operation and protection of a system, such as the case of reclosers and disconnectors. Reclosers are equipment that allows automatic reclosing when network faults occur, having the ability to automatically restore service when the fault is cleared. On the other hand, disconnectors allow connection and disconnection operations under operating or maintenance conditions [6]. 


\section{METHODOLOGIES FOR CALCULATING THE MONITORING FREQUENCY}

\subsection{P-F curve}

The P-F curve (Figure 1) describes from the time a fault starts and continues to deteriorate to a point where it can be detected (the Potential Fault "P" point). From that point on, if it is not detected and appropriate action is not taken, deterioration continues, sometimes at an accelerated rate, until it reaches point " $F$ " of Functional Failure. The time that elapses between the point in which a Potential Fault appears and the point in which it becomes a Functional Fault is known as the P-F interval $[7]$.

This time interval gives the total time that is available to avoid functional failure. To ensure timely recognition of potential failures, the frequency of inspection should be less than the respective P-F interval. The net P-F interval is the actual interval that is counted to avoid functional failure. The magnitude of the net P-F interval depends directly on the determined inspection frequency [8].

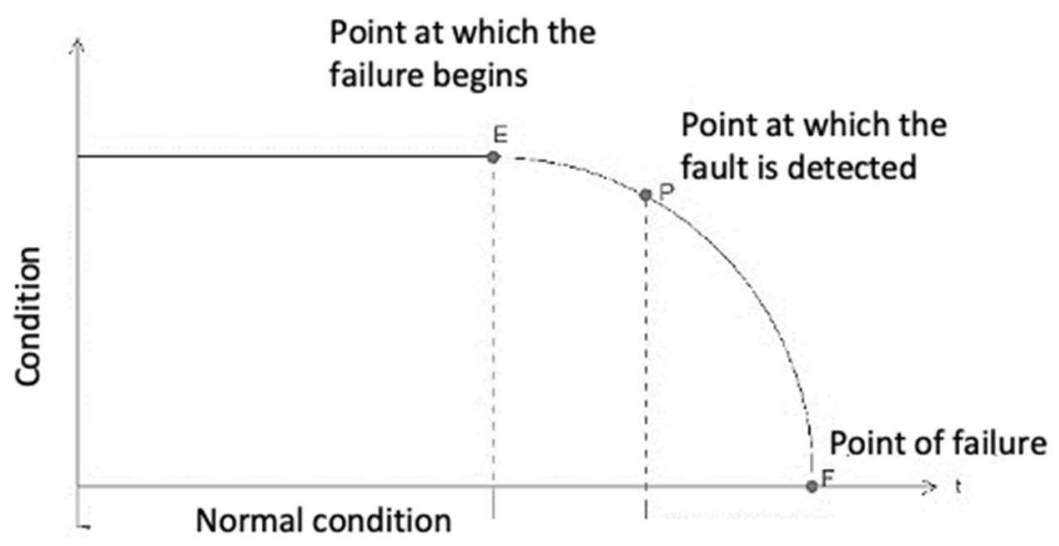

Figure 1: P-F Curve

\subsection{Pareto Chart}

The Pareto chart is the result of applying a simple statistical technique that allows discriminating the most influential actors or parameters in some study variables, through a graphical analysis method; therefore, it allows identifying the critical elements of a system [9]. With the Pareto diagram, we seek to analyze and identify the most likely causes of events that occur in a process or activity within a set. The principle of this method establishes that $20 \%$ of the causes (Vital) will produce $80 \%$ of the effects, while $80 \%$ of the causes (Trivial) will produce $20 \%$ of the effects. Pareto showed that this rule of thumb can be applied to many aspects of life, some of which is the analysis of system failures and the quality control of products [10].

To carry out Pareto's analysis a list of items must be made (generally the 10 items with the greatest impact "Top Ten" are used), organized from highest to lowest. While in the secondary axis is added the percentage of importance that each event contributes. This graph allows us to immediately identify the events where efforts should be focused to execute corrective actions and obtain the best results (Table 1). 
Table 1: Pareto Example Data

\begin{tabular}{|l|c|c|}
\hline \multicolumn{1}{|c|}{ Failure Mode } & Events & Pareto \\
\hline Abnormal Instrument Reading & 1050 & $38 \%$ \\
\hline External leakage of process media & 650 & $59 \%$ \\
\hline Breakage & 320 & $70 \%$ \\
\hline Obstruction / restriction & 300 & $80 \%$ \\
\hline It does not work as it should & 170 & $86 \%$ \\
\hline Wrong operation & 125 & $90 \%$ \\
\hline Structural deficiency & 100 & $93 \%$ \\
\hline Minor problems in service & 50 & $95 \%$ \\
\hline Vibration & 25 & $96 \%$ \\
\hline Mechanical Damage & 3 & $96 \%$ \\
\hline
\end{tabular}

\subsection{Cost Factor, Failure and Adjustment}

The value of the interval between predictive inspections will be directly proportional to three factors: cost factor, failure factor and adjustment factor [11]. Thus, the mathematical relationship is defined in (1).

$I=C \times F \times A(1)$

Where $\mathrm{C}$ is the cost factor, $\mathrm{F}$ is the failure factor and $\mathrm{A}$ is the adjustment factor.

The cost factor $\mathrm{C}$ ratio is given by (2)

$C=\frac{C i}{C f}(2)$

Where $\mathrm{Ci}$ is the cost of a predictive inspection (in monetary units) and $\mathrm{Cf}$ is the cost incurred for not detecting the failure (in monetary units). Therefore, $\mathrm{C}$ is a dimensionless factor.

The ratio of the failure factor $\mathrm{F}$ is given by (3).

$F=\frac{F i}{K}(3)$

Where $\mathrm{Fi}$ is the number of failure modes that can be detected using the predictive technology (expressed in failures per inspection) and $K$ is the rate of failures presented by the equipment and that, also, could be detected by the predictive technology to be applied (expressed in failures per year).

The probability of occurrence of more than zero failures is expressed as

$1-P(0, \Lambda)=1-e^{-\Lambda}(4)$

Where $\mathrm{P}(0, \lambda)$ is Poisson's cumulative distribution function for an occurrence value of 0 and a half $\lambda$.

Thus, the adjustment factor will be equal to

$A=-\ln \left(1-e^{-\Lambda}\right)(5)$

Following the above, the predictive inspection interval is defined as

$I=-\frac{C i \times F i}{C f \times \Lambda} \times \ln \left(1-e^{-\Lambda}\right)(6)$

Expressed in years per inspection. Being the inverse of this ratio equal to the inspection frequency (f), it 
will be expressed in inspections per year.

\section{APPLICATION OF THE METHODOLOGIES}

\subsection{P-F curve}

To determine the P-F interval you have the report of events detected by the thermography technique for equipment 1 (Recloser) presented in Table 2.

Table 2: Recloser Data

\begin{tabular}{|l|l|l|l|l|}
\hline Equipment & \multicolumn{1}{|c|}{ Name } & \multicolumn{1}{|c|}{ Week } & \multicolumn{1}{|c|}{ Status of failure } \\
\hline 1 & RC (Recloser) & Year 2015 Week 21 & alarm & To be determined \\
\hline 1 & RC (Recloser) & Year 2015 Week 23 & alarm & To be determined \\
\hline 1 & RC (Recloser) & Year 2015 Week 32 & investigation & To be determined \\
\hline 1 & RC (Recloser) & Year 2016 Week 02 & monitoring & Corrosion/Dirt \\
\hline 1 & RC (Recloser) & Year 2016 Week 04 & investigation & none \\
\hline 1 & RC (Recloser) & Year 2016 Week 09 & Ok & loose connection \\
\hline 1 & RC (Recloser) & Year 2016 Week 25 & alarm & Corrosion/Dirt \\
\hline 1 & RC (Recloser) & Year 2016 Week 29 & investigation & none \\
\hline 1 & RC (Recloser) & Year 2017 Week 37 & harsh & loose connection \\
\hline
\end{tabular}

As suggested, the P-F interval is determined for only one failure mode at a time for one equipment. In this case, the loose connections will be checked, from which it can be inferred from the previous table that until 2016/week 09 a failure was detected with the equipment status "ok" (point P), and by 2017/week 37 this failure caused the equipment status to change to "severe" (point F). With this analysis, we have the following P-F curve.

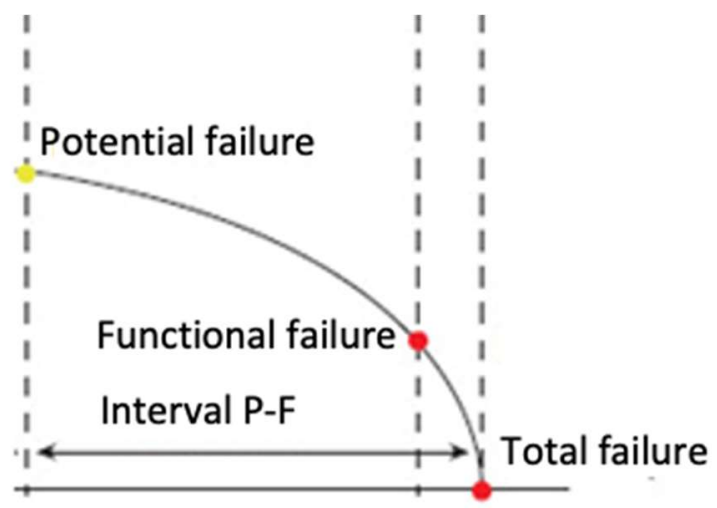

Figure 2: P-F Curve Equipment 1 for loose connection detected with thermography 
With the determined P-F interval it can be inferred that the inspection interval should be less than 80 weeks, $50 \%$ of the P-F interval is taken as a criterion to determine the inspection interval, that is to say, the inspections will be carried out every 40 weeks. Hence the number of Inspections per year $=40$ week/52week $=1.3 \approx 1$. Therefore, the result is finally 1 inspection per year. This same step by step has to be done for each of the teams that are the object of the CBM activities.

\subsection{Pareto Chart}

For the case study, we take the thermographic inspection history data for recloser and disconnector equipment in the field where we have information on the number of inspections in a time delta together with the number of findings found in these and additionally we have the MTBF of each of the equipment as shown in Table 3.

Table 3: MTBF oil field equipment

\begin{tabular}{|c|c|c|c|c|}
\hline Equipment & $\begin{array}{c}\text { Number of } \\
\text { inspections }\end{array}$ & $\Delta$ days & $\begin{array}{c}\text { Number } \\
\text { of finds }\end{array}$ & MTBF \\
(Months)
\end{tabular}

Initially, the teams are ordered from the lowest to the highest MTBF and select the data that have a delta time greater than one year, so you have a top ten list of representative events. Then, we take the historical data from the previous table and convert them all to the same time unit (for this study we work with annual values), these are organized from more to fewer findings in the teams resulting from the inspections. Finally, with the number of annual findings, the Pareto percentage is calculated. The results are tabulated below (Table 4). 
Table 4: MTBF oil field equipment

\begin{tabular}{|l|l|l|l|}
\hline Equipment & $\begin{array}{l}\text { Annual } \\
\text { inspections }\end{array}$ & $\begin{array}{l}\text { Annual } \\
\text { findings }\end{array}$ & Pareto \\
\hline 1 & 5,14084507 & 1,4688129 & $29 \%$ \\
\hline 2 & 1,949265688 & 0,9746328 & $48 \%$ \\
\hline 3 & 2,286967419 & 0,914787 & $66 \%$ \\
\hline 4 & 2,744360902 & 0,4573935 & $75 \%$ \\
\hline 5 & 1,829573935 & 0,4573935 & $84 \%$ \\
\hline 6 & 1,798029557 & 0,4495074 & $93 \%$ \\
\hline 7 & 2,937625755 & 0,3672032 & $100 \%$ \\
\hline 8 & 1,931216931 & 0 & $100 \%$ \\
\hline 9 & 2,896825397 & 0 & $100 \%$ \\
\hline 10 & 2,896825397 & 0 & $100 \%$ \\
\hline
\end{tabular}

Applying the principle of the Pareto chart, they identify which teams had more findings in the inspections and thus relate the number of findings necessary for their detention. What was done is to take the inspections of the teams that represent the events over $80 \%$ and calculate their arithmetic average, rounding this average to a whole number to finally obtain as a result 3 inspections per year.

\subsection{Cost Factor, Failure and Adjustment}

To calculate the cost factor, it is required to know the cost of applying a predictive inspection, which depends on the cost of the Human Hours $(\mathrm{HH})$ of monitoring and analysis required by the equipment. For a thermographic inspection in reclosers and disconnectors, the costs are presented in Table 5.

Table 5: Balance of the Resource

\begin{tabular}{|l|c|c|}
\hline \multicolumn{1}{|c|}{ Resource } & Monitoring & Analysis \\
\hline Human Hours $(\mathrm{HH})$ & 1,5 & 1 \\
\hline Cost & $\$ 83.000$ & $\$ 53.000$ \\
\hline Total & $\$ 124.500$ & $\$ 53.000$ \\
\hline
\end{tabular}

From Table 5 it is determined that the cost is $\$ 177.500$ of a predictive inspection is given by

$$
C i=\text { Monitoring Cost }+ \text { Analysis Cost (7) }
$$


The cost of not detecting a $\mathrm{Cf}$ failure corresponds to the most severe cause that can be generated by equipment failure, which corresponds to the cost of the total loss of function of the equipment and the affectation of the system. Since reclosers and disconnectors are the equipment in charge of system protection and operation, when a failure occurs in this equipment, field production is affected, since they can isolate critical equipment in the operation, generating high losses represented by the number of oil barrels that are not produced. For calculation purposes, it is estimated that the cost of not detecting a failure represents the loss of 300 barrels, with an average price of US\$ 48 per barrel. Therefore, Cf equals US\$ 14400. From $\mathrm{Ci}$ and $\mathrm{Cf}$ the cost factor is obtained, applying the (8).

$$
C=\frac{C i}{C f}=\frac{U S \$ 59,17}{U S \$ 14400}=0,00411(8)
$$

The fault factor depends on the number of fault modes that can be detected by applying predictive technology and the fault rate, so using the fault modes established by ISO 14224, 5 fault modes can be detected for reclosers and disconnectors. [7] To obtain the failure rate, the MTBF of each equipment is calculated and the average is calculated for reclosers and disconnectors, obtaining an MTBF of 15 months and 11 months, respectively. From the MTBF, the inverse of the MTBF is calculated to find the value of $\lambda$ as presented in the (9).

$$
\lambda=\frac{1}{M T B F}(9)
$$

Table 6 shows the Cost Factor, Failure, Adjustment, Inspection, and Optimal Frequency, obtaining as the optimal frequency in reclosers 1,21 times per year which is equivalent to inspections every 297 days and in isolators 1,81 times per year which represents an inspection frequency every 198 days.

Table 6: Cost Factor, Failure and Adjustment Oil field equipment

\begin{tabular}{|l|c|c|c|c|c|}
\hline Equipment & $\boldsymbol{\lambda}$ & $\begin{array}{c}\text { Fault } \\
\text { Factor }\end{array}$ & $\begin{array}{c}\text { Adjustment } \\
\text { Factor }\end{array}$ & Inspection & $\begin{array}{c}\text { Optimal } \\
\text { Frequency }\end{array}$ \\
\hline Reclosers & 0,068 & 73,79 & 2,72 & 0,826 & 1,21 \\
\hline Disconnector & 0,091 & 55 & 2,44 & 0,55 & 1,81 \\
\hline
\end{tabular}

\section{ANALYSIS OF RESULTS}

Making the optimal inspection frequency analysis of thermographs for reclosers and disconnectors, through the different methodologies: P-F curve, Pareto and Cost Factor diagrams, failures and adjustment, we obtain the results shown in Table 7.

Table 7: Result of optimal frequency

\begin{tabular}{|l|c|c|}
\hline \multicolumn{1}{|c|}{ Methodology } & Reclosers & Disconnector \\
\hline P-F Curve & 1 & 1 \\
\hline Pareto Chart & 3 & 3 \\
\hline $\begin{array}{l}\text { Cost Factor, Failure } \\
\text { and Adjustment }\end{array}$ & 1,21 & 1,81 \\
\hline
\end{tabular}


Since the P-F curve is an empirical method, usually used in the field when there is no historical data of the equipment, it is obtained that at least once a year the assets are inspected. In the P-F curve method, the inspection frequency is obtained simply since a review is made of the field operation experience and the criteria already implemented by the professionals to define the frequencies of the maintenance activities that have given good results so far. The disadvantage of this method is that you can choose from the P-F interval a time that is too small to incur many inspections and therefore increase costs unnecessarily.

The Pareto chart is a more conservative method, since the frequency of monitoring is every 120 days, suggesting more follow-up to the state of the assets, therefore, more resources $(\mathrm{HH})$ are required represented in costs. Applying the Pareto chart method results in an inspection frequency that is better supported by quantitative data from the reporting of historical inspection activities within a group of equipment compared to the P-F curve method which is more qualitative; the disadvantage of implementing this method is that if not enough information is reported from the inspections performed and the findings in these, or the information is incomplete, the quality of the result of the calculation will not be the same. Another disadvantage is that the number of inspections reported for a team may be the result of a follow-up to defective equipment and not a predictive monitoring activity that will influence the outcome.

On the other hand, the method of the cost factor, failure and adjustment as a quantitative method presents a more approximate value for the frequency of inspection, where the costs of the inspections are taken into account and it is based on historical data of operation of the equipment, therefore, when applying an average of data, an adjustment value is applied that allows to diminish the percentage of error and to approximate mathematically modeling the optimal frequency of inspection of the equipment object of study. Finally, can be calculated quantitatively the optimal frequency of inspection when you have good data of the equipment understudy, so concerning the P-F curve would allow calculating more accurately this value, based on the historical information of the operation of the equipment because the P-F curve is a qualitative method, based on the experience of operators, so it has a higher margin of error.

\section{CONCLUSIONS}

Empirically, the frequency of equipment inspection can be determined through the P-F curve based on the expertise of CBM personnel, which is subject to a higher percentage of error and depends on the ability of personnel to anticipate failure.

The Pareto chart allows you to obtain the frequency of asset inspection in a more conservative manner, however, it may not be the most optimal method since it does not represent the most effective cost-benefit ratio.

Finally, using the method of the cost factor, failure and adjustment can be determined the optimal frequency of inspection in a more comprehensive, since it takes into account the benefit-cost of assets, maintaining the reliability of equipment based on their criticality and customer requirements.

\section{ACKNOWLEDGMENTS}

The authors would like to thank the Universidad Distrital Francisco José de Caldas and the LASER research group that supported the development and testing of the project.

\section{REFERENCES}

1. Deepak P. and Dharmaraj A. (2018). Modern Plant Maintenance and Reliability Management Methods. International Journal of Mechanical and Production Engineering Research and Development (IJMPERD), Vol. 8, Issue 3, Jun 2018, 791-802. 
2. Ahmad, R. \& Kamaruddin, S. (2012). A review of condition-based maintenance decision-making. European Journal Industrial Engineering. 6(5):519-541.

3. Gillespie, A. (2015). Condition Based Maintenance: Theory, Methodology, \& Application. Conference: Reliability and Maintainability Symposium.

4. Norman, M. A., Abouel, E. S., Al-Shareyea, A. \& Kaid, H. (2019). Overview of predictive condition based maintenance research using bibliometric indicators. Journal of King Saud University - Engineering Sciences.31(4):355-367.

5. Balasubramanian A., (2018). A New Model for Consistency Centered Maintenance in Petroleum Refinery. International Journal of Mechanical and Production Engineering Research and Development (IJMPERD), Vol. 8, Issue 1, Feb 2018, 791-798.

6. Puladasu S., (2015). Protection of Distribution Systems with Fuel Cells Based Distributed Generation. International Journal of Mechanical and Production Engineering Research and Development (IJMPERD), Vol. 5, Issue 1, Jun 2015, 19-28.

7. Keith Mobley K., (2002). An Introduction to Predictive Maintenance. Elsevier Science. ISBN 0-7506-7531-4.

8. Bousdekis, A., Magoutas, B., Apostolou, D. and Mentzas, G. (2015), A Proactive Decision Making Framework for ConditionBased Maintenance, Industrial Management \& Data Systems, Vol. 115 No. 7, pp. 1225-1250.

9. Vijayalakshmi. G, Nirupama Devi. $K$ \& Srinivasa Rao. K. (2014). Inventory Model for Deteriorating Items Having Two Component Mixture of Pareto Lifetime and Time Dependent Demand. International Journal of Mathematics and Computer Applications Research (IJMCAR), Vol. 4, Issue 5, Oct 2014, 15-28.

10. Desai, T. N., \& Shrivastava, R. L. (2008). Six Sigma-A New Direction to Quality and Productivity Management. Proceedings of the World Congress on Engineering and Computer Science, pp. 22-24.

11. Adenikinju, A. F. (2003). Electric infrastructure failures in Nigeria: a survey-based analysis of the costs and adjustment responses. Energy policy, 31(14), 1519-1530. 

